\title{
Experimental and Numerical Analysis of Fatigue Crack Growth in Integral Skin-Stringer Panels
}

\author{
Abulgasem SGHAYER, Aleksandar GRBOVIĆ, Aleksandar SEDMAK, Mirko DINULOVIĆ, Ines GROZDANOVIC, Simon SEDMAK, \\ Blagoj PETROVSKI
}

\begin{abstract}
Experimental and numerical analysis of fatigue crack growth in integral skin-stringer panels, produced by means of laser beam welding (LBW), is performed. Since this type of panel is used in airframe construction, fatigue and damage tolerance is of paramount importance, since aircrafts must be tolerant to relatively large fatigue cracks. Firstly, using extended finite element method (XFEM), the fatigue crack growth on the simple flat plate made of AL-AA 6156T6/2.8 mm was simulated, and results were compared with values obtained in the experiment. The same approach was taken to simulate the fatigue behaviour and crack propagation of the real skinstringer panel (four stringers, laser beam welded). It was found that the results obtained for stress intensity factors (SIFs) $K_{\mathrm{I}}, K_{\|}, K_{\mathrm{III}}$ and $K_{\text {eff }}$ along the crack front, are close to the experimental results, leading to conclusion that the XFEM method can be successfully used in prediction of fatigue life of complex airframe structures, such as laserbeam welded skin-stringer panels.
\end{abstract}

Keywords: crack growth rate; integral skin-stringer structures; SIFs; XFEM

\section{INTRODUCTION}

Well-designed aircraft structure is one that is lightweight and cost-efficient and that has the ability to perform its intended function during service life. This is especially true for commercial aircraft structures which have a complex shape with the fuselage shell composed of stressed skin, longitudinal stringers and circumferential frames. The skin is connected to the stringers and frames mostly by rivets (Fig. 1) and these joints are subjected to a major loading of differential internal pressurization. Riveted skin-stringers structures have been introduced in aircraft fuselage assemblies since the 1940's and are still widely used. When the fuselage is pressurized and depressurized during take-off/landing cycles, the skin of fuselage expands and contracts resulting in metal fatigue. Due to the presence of drilled rivet holes, the fuselage skin has a large number of stress locations which may lead to crack initiation.

Aircrafts must be designed to tolerate relatively large fatigue cracks, but safety measures must be taken before cracks reach critical lengths and cause catastrophic failures. Damage tolerant designs use fracture mechanics data and analysis to predict crack growth rates and critical crack lengths. To successfully prevent the failure, it is necessary to estimate the number of cycles of the external load that will grow crack to critical length.

Fatigue crack initiation and growth, as well as fracture resistance and corrosion issues associated with riveted structures, are well understood and it seems difficult to get significant improvements in riveting technology regarding the extension of the fuselage fatigue life. However, the development of welding technology, like LBW, enabled production of integral skin-stringer structures, which in turn reduced the riveted joint applications [1]. Integral skinstringer structures (Fig. 2), which enable skin and stringers to behave as a continuum, are more suitable for improvements even though they might be poor at damage tolerance performance. Compared to the conventional riveted structures, integral skin-stringer structures are lighter and cheaper, easier to inspect and have fewer holes with high stresses suitable for crack initiation. Recent developments of advanced welding technologies have led to further reduction of weight and fabrication costs [2-5], including LBW, which has been successfully applied for manufacturing of skin-stringer curved panels for various civilian aircrafts in Europe, and is also considered for buttjoints in fuselage and wing structures $[6,7]$.

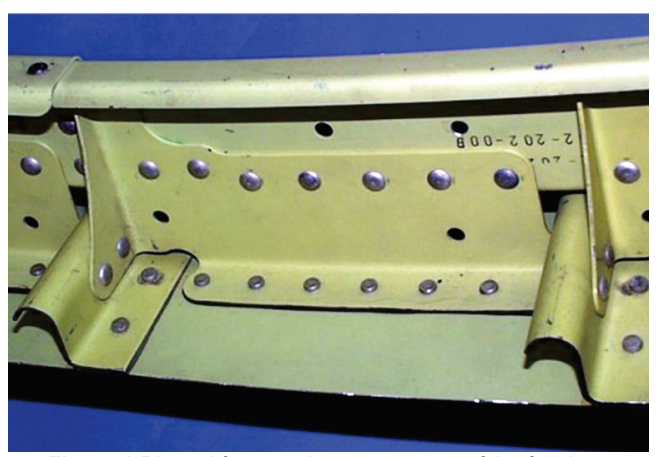

Figure 1 Riveted frame-stringers structure of the fuselage

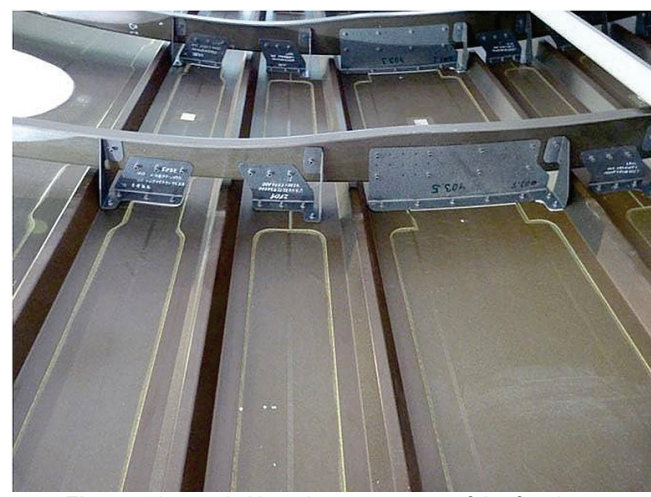

Figure 2 Integral skin-stringer structure of the fuselage

Despite its numerous advantages, joints made by LBW may still suffer from seam imperfections like notches or holes which affect fatigue life significantly. Despite manufacturing precautions, cracks may appear in integral skin-stringer structure and reduce its stiffness and the load-carrying capacity. The safe operation of pressurized fuselage structure is ensured through the operation of damage tolerant design and evaluation, 
which intended to certify that fatigue, corrosion, or other mechanisms should cause crack to grow within the operational life, so that the remaining structure can withstand reasonable loads without failure or excessive structural deformation until the damage is detected. Two types of damage most frequently associated with the structural integrity of the fuselage are longitudinal cracks under hoop stresses (induced by cabin pressurization) and circumferential cracks under stresses from vertical bending of the fuselage [8]. A critical element of damage tolerant design in pressurized fuselage is the ability to predict the growth rate of fatigue cracks under known applied loading.

The crack growth stage is studied by using stress intensity factor (SIF), as the basic parameter defining the stress field near the crack tip. There are many methods used in the computational mechanics for SIFs calculations. The crack opening displacement (COD) method, as well as the force method, was popular in early applications of finite element method (FEM) to fracture analysis [9]. The virtual crack extension (VCE) methods, proposed by Hellen [9], led to increased accuracy of SIF results. The VCE method requires only one complete analysis of a given structure to calculate SIF. Both the COD and VCE methods can be used to calculate SIF for all three fracture modes. However, additional complex numerical procedures have to be applied to get results.

FEM has been used for decades for calculating SIFs, but it has some restrictions in crack propagation simulations mainly because the finite element mesh needs to be updated after each propagation step in order to track the crack path. Extended finite element method (XFEM) suppresses the need to mesh and remesh the crack surfaces and is used for modelling different discontinuities in 1D, 2D and 3D domains. XFEM allows for discontinuities to be represented independently of the FE mesh by exploiting the Partition of unity finite element method, [10]. In this method enrichment functions are added to the displacement approximation as long as the partition of unity is satisfied. The XFEM uses these enrichment functions as a tool to represent a nonsmooth behaviour of field variables.

Due to the relatively short history of the XFEM, commercial codes which have implemented the method are not prevalent. There are however, many attempts to incorporate the modelling of discontinuities independent of the FE mesh by either a plug-in or native support. Cenaero [11] has developed a crack growth prediction add-in Morfeo/Crack for Abaqus which relies on the implementation of the XFEM method available in Abaqus software. Problems involving static cracks in structures, evolving cracks, cracks emanating from voids etc., were numerically studied and the results were compared against the analytical and experimental results to demonstrate the robustness of the XFEM and precision of Morfeo/Crack for Abaqus [12, 13].

The cracks are represented with the help of two signed distance functions that are discretized on the same mesh as the displacement field with first-order shape functions. Method for representing the cracks in this application is exactly the same as described in [14]. After each step of the propagation simulation, the SIFs are computed from the numerical solution at several points along the crack fronts. Interaction integrals are used to extract the mixed-mode SIFs with the help of auxiliary fields. After that Paris-Erdogan fatigue crack growth model can be used for evaluation of the number of cycles that will grow crack to the critical length, as shown in [15-17].

XFEM is still not fully recognized and needs to prove its practical worth in order to be generally acknowledged. Results obtained by using XFEM for a complex 3D geometry are still not regarded as reliable without experimental checks. The purpose of this paper is to demonstrate that reliable fatigue life predictions can be obtained with crack growth simulation applied to threedimensional integral skin-stringer structure using the extended finite element method. Results and conclusions given here should contribute to making a more objective judgment about XFEM usefulness in solving wide range of engineering problems, especially those related to the commercial aircraft design.
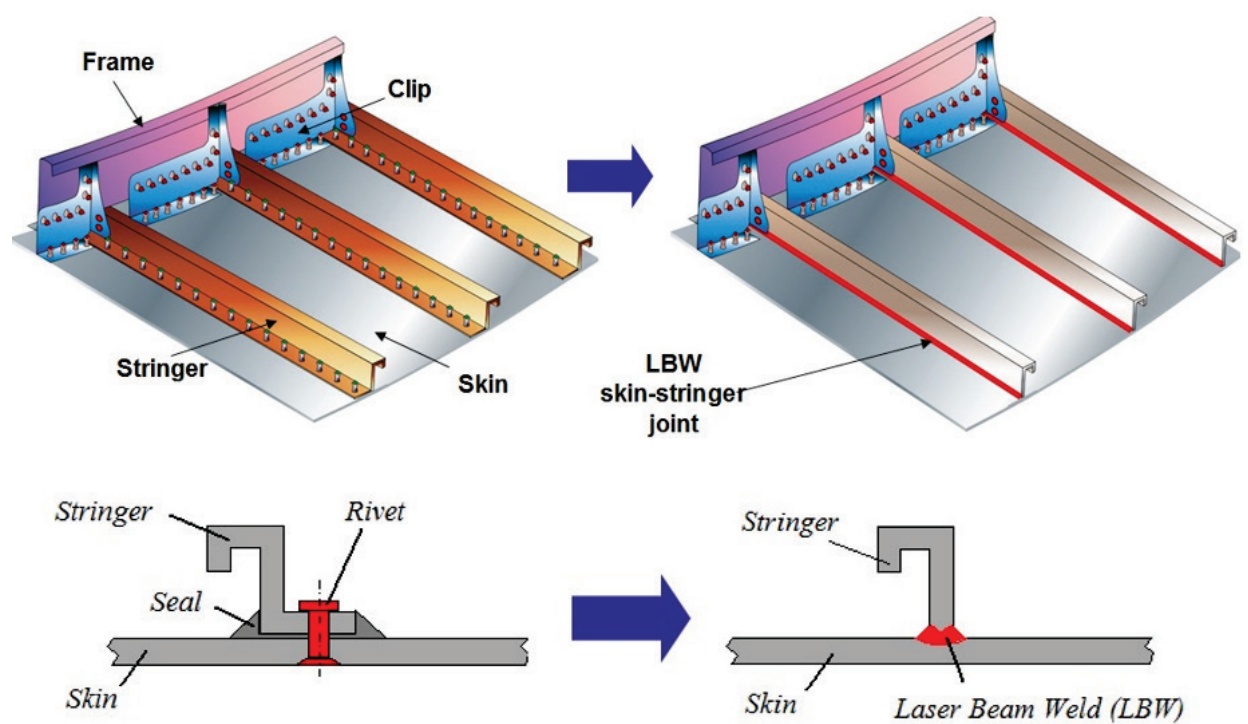

Figure 3 Differential vs. integral structure of the fuselage 


\section{EXPERIMENTAL WORK USED AS A REFERENCE}

The basis for this paper is the report presented on "European Workshop on Short Distance WELding Concepts for AIRframes - WEL-AIR" on June 2007 that is created on the basis of damage tolerance analysis of 4stringer flat panels that are jointly made by the Airbus division in Bremen and GKSS Research Center Geesthacht (Hamburg) - Germany. By courtesy of project participants, the results of fatigue test of laser beam welded short distance clip welds using 4-stringer flat panels [18], were available for inspection and they were used as reference for verification of fatigue life values obtained by numerical simulations using XFEM.

The main idea of the project was to perform fatigue testing of integral structures that should replace the conventional differential structures (Fig. 3) where joints are obtained using rivets. Panels with stringers are traditionally used in fuselage production; therefore, Airbus has decided to test this type of geometry.

Integral skin-stringer structure is obtained using LBW, and fatigue life testing was performed on panel under tension containing growing damage perpendicular to the stringer weld joint (circumferential crack, Fig. 4). Panel geometry with stringers and their dimensions is presented in Fig. 5.

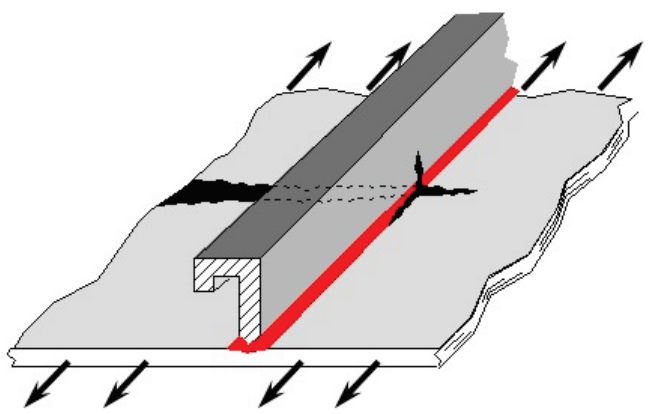

Figure 4 Circumferential crack on the panel under tension
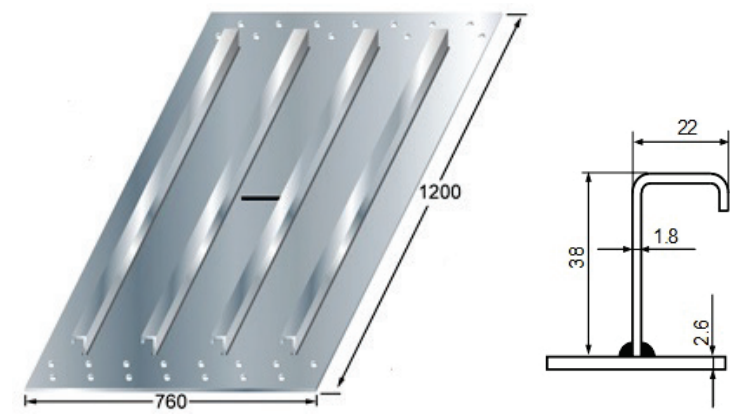

Figure 5 Dimensions of the 4-stringer panel made of 6156 T6 (LB welded by AIRBUS)

The 4-stringer panels with the initial crack lengths 14 $\mathrm{mm}$ were tested on a standard tensile machine, varying the maximum applied tensile force (with constant amplitude and stress ratio). Different aluminium alloys (6156T6, 2139T8, 6156T4) were tested. Their fatigue characteristics, represented by Paris coefficients, were determined by testing the base metal panels without stringers (Fig. 6). Base metal panels dimensions, tension force and initial crack lengths were identical to dimensions of 4-stringer panel, and fatigue crack lengths during testing were measured using remote optical microscope.

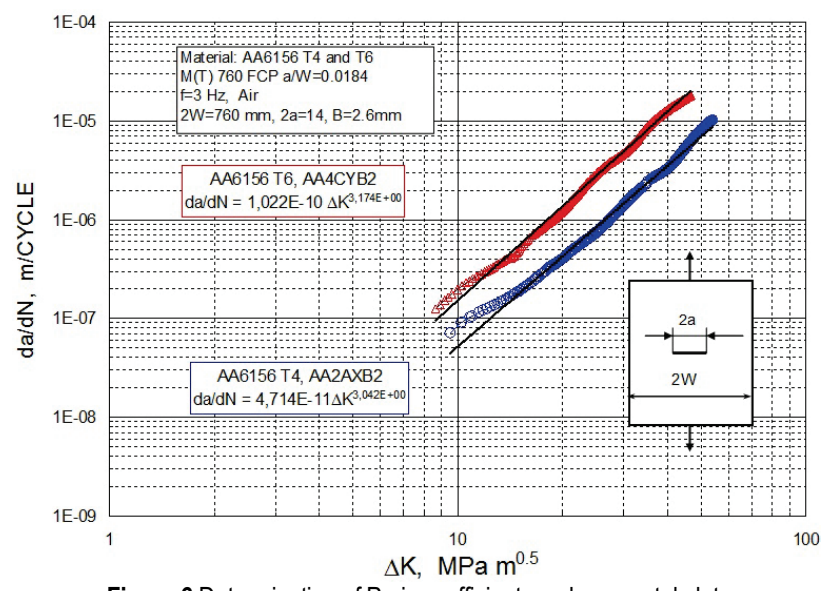

Figure 6 Determination of Paris coefficients on base metal plate

\section{NUMERICAL SIMULATIONS USING XFEM}

As already explained and presented in [19], the main idea of numerical modelling was, firstly, to test XFEM by making FE model of base metal plate with initial crack (Fig. 7), simulating the real loads from experiment, and consequently comparing the number of cycles obtained numerically to the number of cycles obtained experimentally.

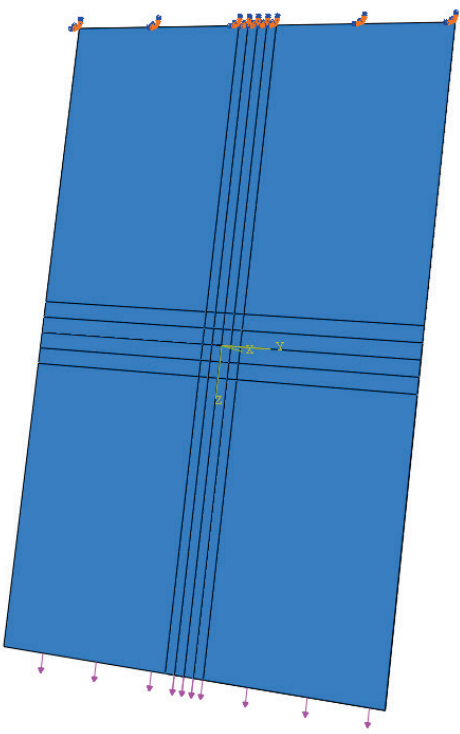

Figure $7 \mathrm{FE}$ model of base metal plate with initial crack, [19]

Base metal plate was chosen as it had simple geometry, and because the calculated values of SIF could be verified using other methods or can be even found in the literature. The second step was FE modelling of 4stringer panel (Fig. 5) and determination of the number of load cycles that would grow crack to critical length that will then be compared to number of cycles obtained in experiment with real 4-stringer structure. In both simulations aluminium alloy AA6156 T6 was used (Young's modulus $E=71000 \mathrm{MPa}$, Poisson's ratio $v=$ 0.33 ), and the FE models of base plate and 4-stringer plate are shown in Fig. 8 and Fig. 15. The loads used in simulations were equal to average values of maximum 
tensile forces over time measured in experiments (obtained due to the courtesy of researchers from GKSS Research Center, Geesthacht). For base metal plate average maximum force was $F_{\max }=112.954 \mathrm{KN}$, while the load ratio $R=0.146$ was determined on the basis of average minimum tensile force measured. Coefficients for Paris equations were adopted on the basis of the values obtained in tests with base metal plates (Fig. 6): $m=$ 3.174 and $C=1.77195 \mathrm{E}-012 \mathrm{MPa} \mathrm{mm}^{1 / 2}$.

Initial crack in the $1^{\text {st }}$ simulation was propagated to length $2 a=275 \mathrm{~mm}$, and Fig. 8 shows its shape after the last growth step. As it can be seen in Fig. 9, the number of cycles predicted by Paris equation incorporated into Morfeo/Crack for Abaqus software is comparable to the number of cycles obtained in one of the experiments with base metal plate (different values of number of cycles were obtained in series of experiments; however, the deviation was not greater than $15 \%$ ).

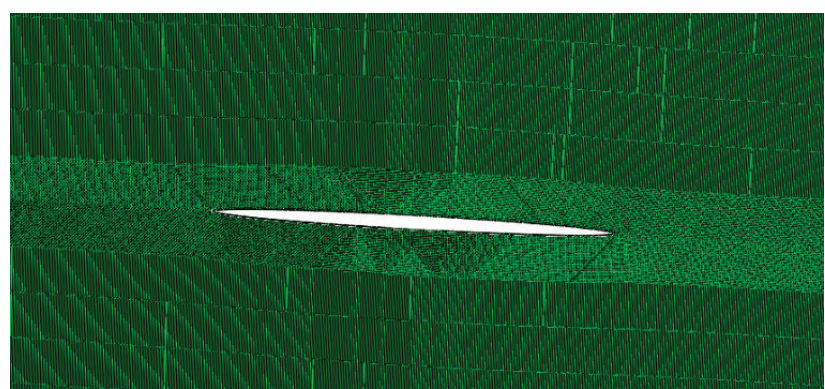

Figure 8 Crack on base metal plate after 260 steps of propagation $(2 a=275$ $\mathrm{mm}),[19]$

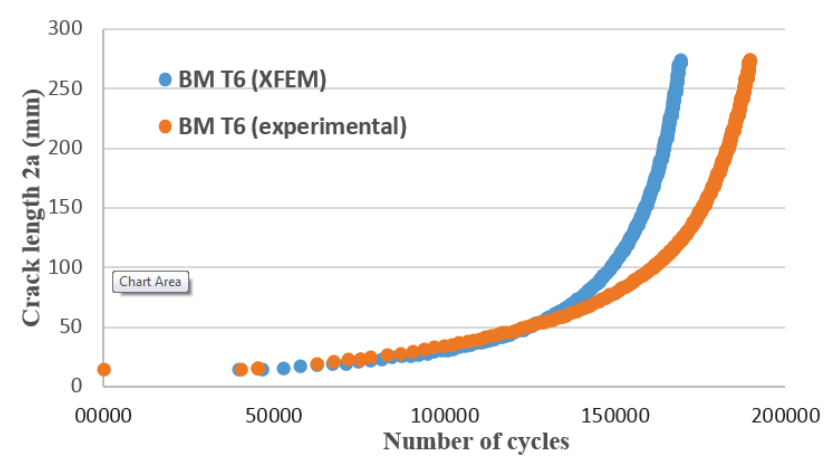

Figure 9 Numbers of cycles obtained in experiment and XFEM simulation (base metal T6), [19]

Fig. 9 shows that in XFEM simulation number of cycles to critical crack length is less than that obtained in experiment (169076 cycles versus 189514 cycles, which is a difference of about 10\%); however, under crack length $2 a=$ $60 \mathrm{~mm}$ (almost linear growth) the numbers of cycles differ insignificantly. This confirms previously drown conclusion [13] that in case of simple geometry XFEM is a fairly reliable method for crack growth rate determination, providing more conservative values compared to the experimental ones. This was confirmed by comparing SIFs values obtained by XFEM and NASGRO software [20], (Fig. 10). It is evident that Morfeo/Crack for Abacus calculates higher Mode I SIFs compared to NASGRO and due to that fact the predicted fatigue life is shorter; however, the number of cycles to critical crack length is on the safe side - predicted life is shorter than that obtained in experiment. (It is important to mention that NASGRO calculates SIFs at the tip of the 2D crack, while
Morfeo/Crack for Abaqus calculates SIFs at the nodes of 3D crack front; in Fig. 10 maximum values of SIFs along crack fronts are given.)

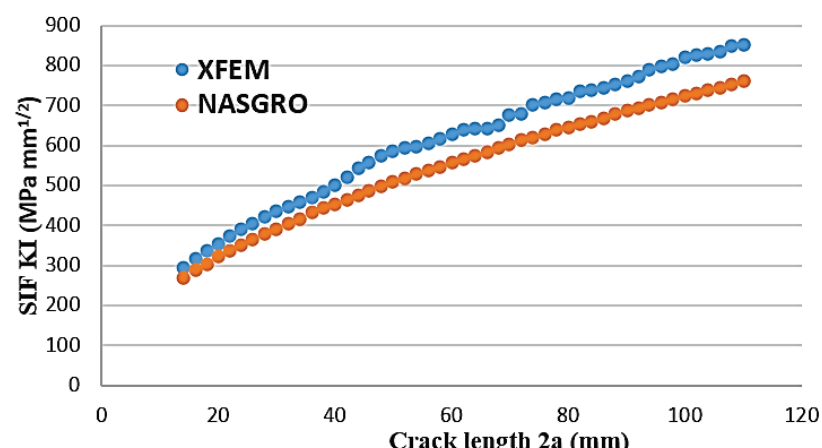

Figure 10 SIF values obtained in NASGRO software and XFEM simulation (base metal T6)

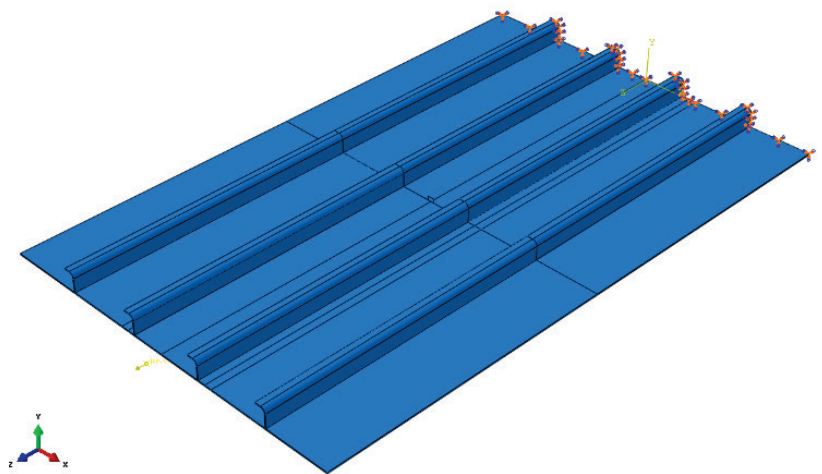

Figure 11 Model of 4-stringer plate with 3D crack used in simulation, [19]

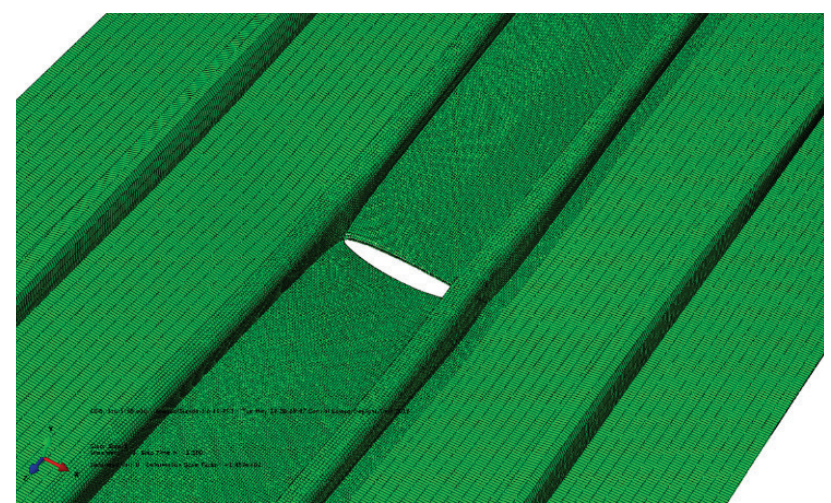

Figure 12 Crack in 4-stringer plate after 68 steps of propagation

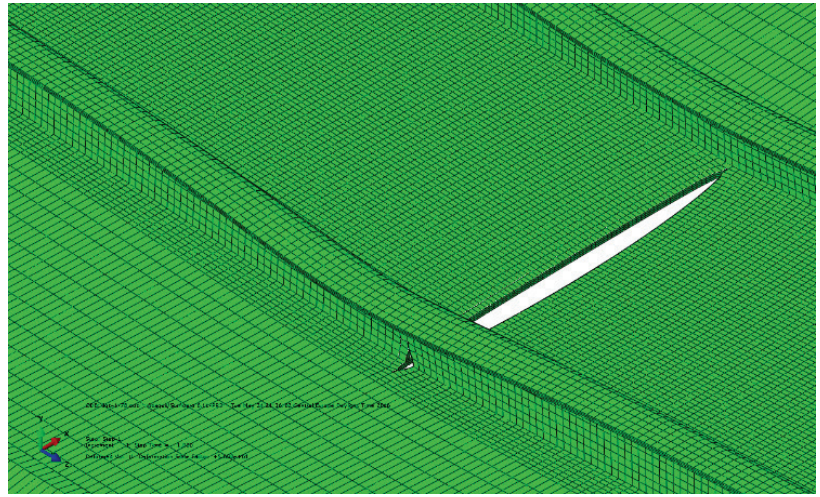

Figure 13 After 78 steps crack begins to spread along the stringer

Having in mind that the researchers from GKSS Research Center have also investigated 4-stringer plates with middle crack, the $2^{\text {nd }}$ simulation was carried out on 
the model shown in Fig. 11. FE model consisted of 322404 nodes and 237600 linear hexahedral elements of type C3D8R. Stringers and skin were modelled in CATIA v5 as a one part (not assembly) in order to simulate integral structure which enables skin and stringers to behave as a continuum. Initial crack (length $2 a=14 \mathrm{~mm}$ ) was propagated in 160 consecutive steps (Figs. 12 to 15 ) and SIFs were calculated. In order to validate the results of simulation the values of crack growth rate obtained in XFEM simulation have been compared to available experimental crack growth rate values shown in Fig. 16.

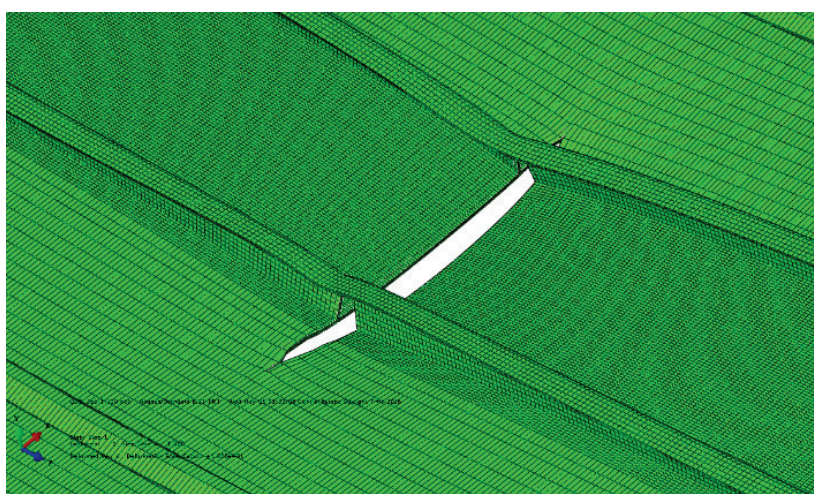

Figure 14 Crack after 130 steps of propagation: both stringers are highly damaged

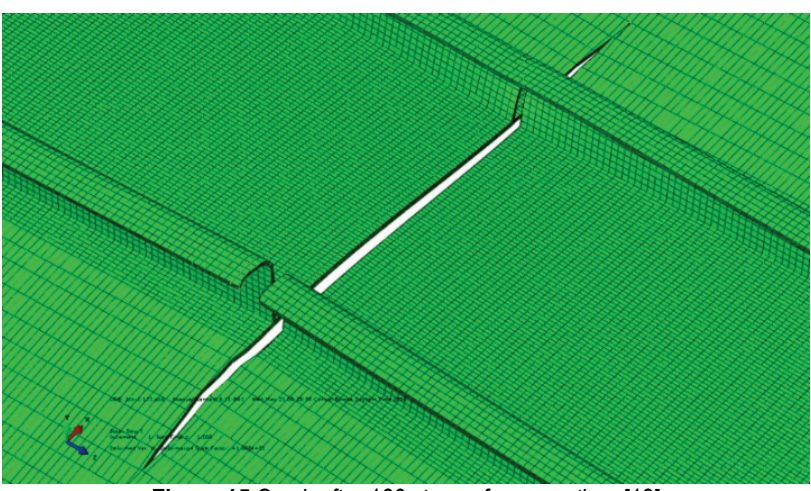

Figure 15 Crack after 160 steps of propagation, [19]

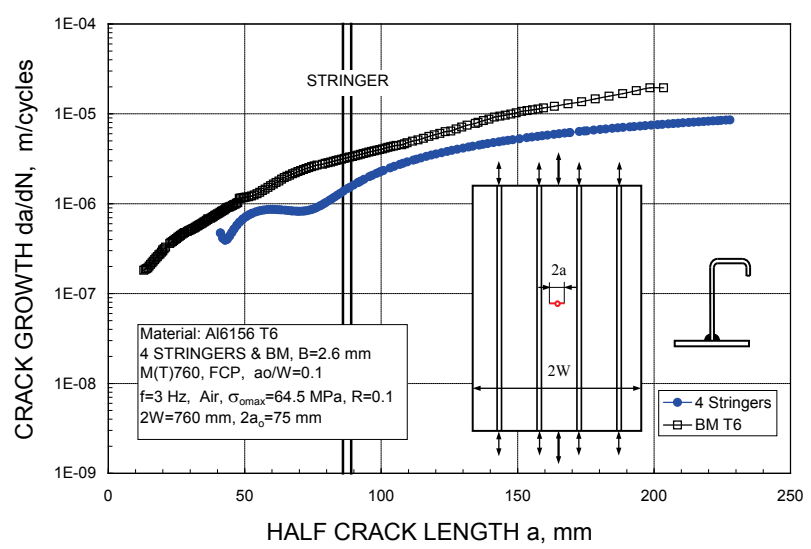

Figure 16 Comparison of the crack growth rate for the base metal plate (black dots) and 4-stringer plate (blue dots) obtained in the experiment, [18]

As it can be seen in Fig. 17, the numerical values are very close to experimental ones. Finally, Fig. 18 shows comparisons of the number of cycles obtained in experiment with base metal plate and number of cycles obtained in simulation with 4-stringer plate. Reason why number of cycles in simulation was not compared to number of cycles in experiment with 4-stringer plate is simple: number of cycles in experiment was not available to the authors of this paper.

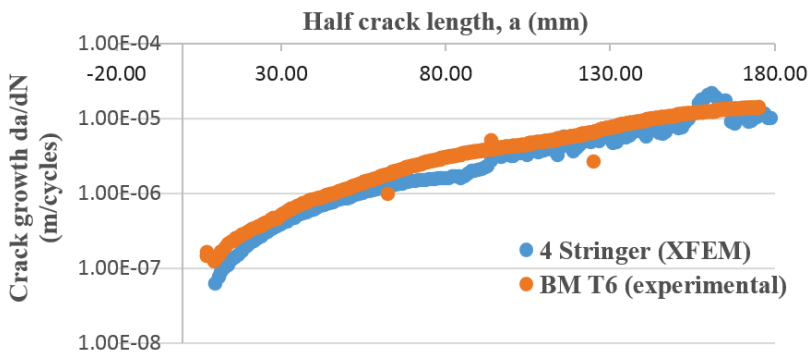

Figure 17 Comparison of the crack growth rate for the base metal plate obtained in the experiment, [18] and 4-stringer plate obtained in simulation with XFEM

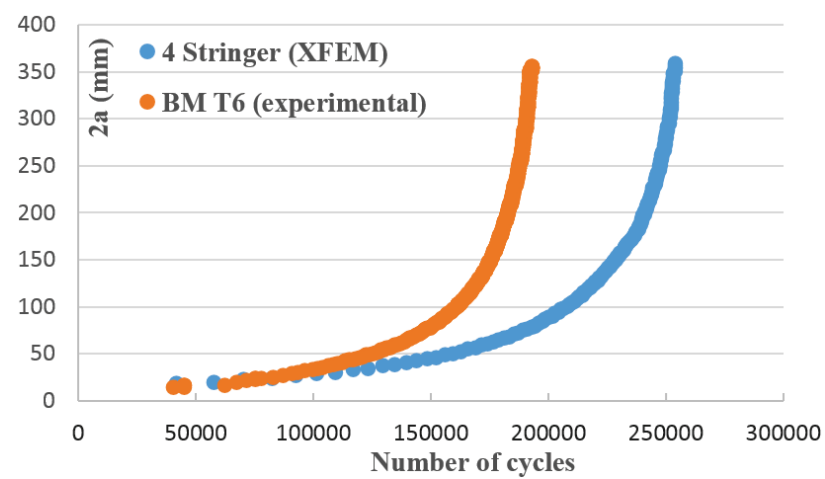

Figure 18 Number of cycles for base metal plate and 4-stringer plate, numerical and experimental, [19]

\section{DISCUSSION AND CONCLUSIONS}

Until the development of XFEM and its integration in existing FE software packages, the numerical simulations of crack propagations through complex 3D structures (similar to those presented in this paper) were practically impossible or - in the best case - very complex and with limited choice of crack shape (as it was the case with FRANC3D software [21]). Also, there was a problem with meshing, because after each step of the crack propagation new FE mesh around the crack front had to be generated which affected the accuracy of results and calculation time, especially for growth simulations of very long cracks.

With XFEM the need for new mesh creation after each step is eliminated and, as it can be seen in Figs. 12 to 15, the crack spreads all the time through unchanged mesh and can reach very long length. The shape and the position of the initial crack depend on the user and there are no limits regarding these issues, whereby simultaneous multiple cracks' growths can also be simulated, as presented in [22, 23]. This is of great importance for fatigue life estimation of aircraft structures such as fuselage with riveted joints which are very often exposed to multiple site damage (MSD).

Estimation of fatigue life of integral aircraft structures, the subject of this paper, is also very important although the possibility of crack occurrence in integral structure is lower than in the case of differential structure. XFEM can play a significant role in this subject and may reduce to a minimum the number of experimental verifications and so fulfil one of the requirements mentioned at the beginning of this paper: cost-efficient design. The results of numerical simulations based on 
XFEM presented in this paper are quite well correlated with experimental values, which is particularly true for the simulation of crack propagation on 4-stringer plate. By analysing the results presented in Fig. 16 (taken from experiment) and Fig. 17 (simulation results for 4-stringer plate) it can be concluded that XFEM gives good predictions of crack growth rate on complex geometry and that the shape of the graph $\mathrm{d} a / \mathrm{d} N$ vs. crack length in Fig. 17 is very similar to the shape of the graph in Fig. 16 (blue dots).

There are, of course, some differences due to the fact that the initial length of the crack in experiment was $2 a_{0}=$ $75 \mathrm{~mm}$ whereas in simulation $2 a_{0}=14 \mathrm{~mm}$, because intention was to compare 4-stringer plate with base metal plate whose initial crack length was $2 a_{0}=14 \mathrm{~mm}$; as a result graph presented in Fig. 18 was created.

The difference in initial crack's lengths is the reason why crack growth rate in simulation at crack length $2 a=$ $100 \mathrm{~mm}\left(\mathrm{~d} a / \mathrm{d} N \approx 1 \times 10^{-6} \mathrm{~m} /\right.$ cycle $)$ is somewhat larger than the crack growth rate in the experiment; however, in both graphs the slight decline of crack growth rate is notable and after that there is almost constant growth rate as the crack approaches the first stringer $(2 a \cong 180 \mathrm{~mm})$. After the crack starts to propagate along both stringers, the growth rate begins to rise again which is understandable because stringers gradually lose their load carrying capacity and the damage is propagating faster and faster. Fig. 17 shows that the growth is almost logarithmic and that rate tends to the value $(\mathrm{d} a / \mathrm{d} N=$ $1 \times 10^{-5} \mathrm{~m} /$ cycle), while Fig. 18 shows certain variability in values of crack growth rate obtained using XFEM, although logarithmic trend is evident. This is more or less expected as the values of SIFs obtained using Morfeo/Crack for Abaqus depend on the density and quality of FE mesh, but it is evident that during one growth period (155 $\mathrm{mm}<a<165 \mathrm{~mm}$ ) crack growth rates in simulation are slightly above the crack growth rates for base metal plate (the order of magnitude of the differences is $8 \times 10^{-6} \mathrm{~m} /$ cycle. The reason for that might be the fact emphasized earlier in this paper (see Fig. 10) and confirmed in [13] that Morfeo/Crack for Abaqus gives somewhat higher SIFs values compared to experimental ones; as a result, curve for 4-stringer plate obtained using XFEM in Fig. 18 is closer to the experimental curve for base metal plate than it is in reality.

However, Fig. 18 shows that when crack length is $2 a$ $\approx 310 \mathrm{~mm}$ it is growing rapidly and this cannot be allowed on the fuselage structure: precautionary measures must be taken much earlier, approximately when crack length $2 a$ is around $100 \mathrm{~mm}$, e.g. before the crack reaches the first stringer, in order to prevent potential catastrophic consequences. This means that the values of crack growth rate when crack length is approximately $310 \mathrm{~mm}$ are not of great importance and that the differences between XFEM results and experimental values cannot affect fatigue life in this particular case. Even though the differences occur earlier, having in mind that Morfeo/Crack for Abaqus on average gives somewhat higher SIF values, fatigue life obtain in simulation should be shorter than one obtained in experiment which cannot put at risk the safety of the fuselage structure.
Finally, Fig. 18 shows that 4-stringer plate with given stringer dimensions and for given tension force has fatigue life approximately $30 \%$ longer than base metal plate (254274 cycles vs. 194453 cycles), which is the estimation obtained on the basis of Paris law (unfortunately, information on the number of cycles obtained in experiment with 4-stringer plate was not available). There are other equations that can be used to estimate fatigue life under given conditions (NASGRO equation, for instance) and they might give other number of cycles, but not so much different from one presented here. If aircraft designers consider the improvement by $30 \%$ as a not satisfactory, redesign of 4 -stringer panel and consequent tests on new panels would take much time and money. However, using XFEM estimation of the total fatigue life of new structure is relatively easy to obtain and inexpensive, not only for loads used in experiments but for the whole spectrum of loads that might appear during the intended life of structure. And this is the main competitive advantage of XFEM.

\section{REFERENCES}

[1] Munroe, J., Wilkins, K., \& Gruber, M. (2000). Integral Airframe Structures (IAS) - Validated Feasibility Study of Integrally Stiffened Metallic Fuselage Panels for Reducing Manufacturing Costs, NASA/CR-2000-209337, May 2000.

[2] Živković, A., Đurđević, A., Sedmak, A., Tadić, S., Jovanović, I., Đurđević, Đ., \& Zammit, K. (2015). Friction Stir Welding of Aluminium Alloys - T Joints. Structural Integrity and Life, 15(3), 181-186.

[3] Živojinović, D., Arsić, M., Sedmak, A., Kirin, S., \& Tomić, R. (2011). Practical aspects of fail-safe design - calculation of fatigue life of cracked thin-walled structures. Technical Gazette, 18(4), 609-617.

[4] Bayraktar, F. S. (2011). Analysis of Residual Stress and Fatigue Crack Propagation Behaviour in Laser Welded Aerospace Aluminium T-joints, $P h D$ thesis, Technischen Universität Hamburg-Harburg.

[5] Lefebvre, F. \& Sinclair, I. (2005). Micromechanical Aspects of Fatigue in MIG Welded Aluminium Airframe Alloy, Part 2: Short Fatigue Crack Behaviour. Materials Science and Engineering, A 407, 265-272. https://doi.org/10.1016/j.msea.2005.07.014

[6] (1999). Proceeding of the GKSS/TWI Workshop on Friction Stir Welding, GKSS Research Center, Geesthacht, Germany, $3^{\text {rd }}$ May 1999

[7] Braun, R., Dalle-Donne, C., \& Staniek G. (2000). Laser Beam and Friction Stir Welding of 6013-T6 Aluminium Alloy Sheet. Material-wissenschaft und Werkstofftechnik, 31, 1017-1026. https://doi.org/10.1002/1521-4052(200012)31:12<1017::AIDMAWE1017>3.0.CO;2-P

[8] Venkatesha, B. K., Suresh, B. S., \& Girish, K. E. (2012). Analytical Evaluation of Fatigue Crack Arrest Capability in Fuselage of Large Transport Aircraft. International Journal on Theoretical and Applied Research in Mechanical Engineering, 1(1), 13-22.

[9] Hellen, T. K. (1973). The finite element calculations of stress intensity factors using energy techniques. $2^{\text {nd }}$ International Conference on Structural Mechanics in Reactor Technology, Paper G5/3, Berlin.

[10] Babuska, I. \& Melenk, J. M. (1998). The partition of unity method. Int. J. Numer. Meth. Eng., 40, 727-758. https://doi.org/10.1002/(SICl)10970207(19970228)40:4<727::AID-NME86>3.0.CO;2-N 
[11] (2016). Cenaero Morfeo, available at http://www.cenaero.be (last accesed on $4^{\text {th }}$ Septembar 2016.

[12] Petrašinović, D., Rašuo, B., \& Petrašinović, N. (2012). Extended finite element method (xfem) applied to aircraft duralumin spar fatigue life estimation. Tehnički vjesnik, 19(3), 557-562.

[13] Grbović, A. (2012). Investigation of fatigue life in superalloys structural components, $P h D$ Thesis (in Serbian), Faculty of Mechanical Engineering, University of Belgrade, Serbia.

[14] Moës, N., Gravouil, A., \& Belytschko, T. (2002). Non-planar $3 \mathrm{D}$ crack growth by the extended finite element and level sets - Part I: Mechanical model. International Journal for Numerical Methods in Engineering, 53, 2549-2568. https://doi.org/10.1002/nme.429

[15] Živojinović, D., Sedmak, A., \& Grbović, A. (2014). Crack Growth Analysis in Friction Stir Welded Joint Zones Using Extended Finite Element Method. Structural Integrity and Life, 13(3), 179-188

[16] Kraedegh, A., Li, W., Sedmak, A., Grbovic, A., Trišović, N., \& Kirin, S. (2017). Simulation of Fatigue Crack Growth in A2024-T351 "T" Welded Joint. Structural Integrity and Life, 17(1), 3-6.

[17] Balać, M., Grbović, A., \& Petrović, A. (2015). Numerical Predictions of Crack Growth in a Pressure Vessel with Welded Nozzles. Structural Integrity and Life, 15(1), 55-61.

[18] Koçak, M., Petrovski, B., Palm, V. F., Kocik, R., \& Syassen, F. (2007). Damage Tolerance Analysis of Laser Beam Welded Short Distance Clip Welds using 4-Stringer Flat Panels. European Workshop on Short Distance WELding Concepts for AIRframes - WEL-AIR, GKSS Research Center, Geesthacht (Hamburg) - Germany, 13 - 15 June 2007.

[19] Sghayer, A., Grbović, A., Sedmak, A., Dinulović, M., \& Donceva, E. (2017). Fatigue life analysis of skin-stringer panel using XFEM. Structural Integrity and Life, 17(1), 7-10.

[20] (2016). NASGRO, http://www.swri.org/4org/d18/mateng/ matint/nasgro/ (last accessed on 4th September 2016).

[21] (2016). FRANC3D, http://www.fracanalysis.com software.html (last accessed on 4th September 2016).

[22] Kastratović, G., Grbović, A., \& Vidanović, N. (2015) Approximate method for stress intensity factors determination in case of multiple site damage. Applied Mathematical Modelling, 39(19), 6050-6059. https://doi.org/10.1016/j.apm.2015.01.050

[23] Rakipovski, E., Grbović, A., Kastratović, G., \& Vidanović, N. (2015). Application of Extended Finite Element Method for Fatigue Life Predictions of Multiple Site Damage in Aircraft Structure. Structural Integrity and Life, 15(1), 3-6.
Ines GROZDANOVIĆ, Assoc. Prof. PhD

University of Belgrade, Faculty of Mining and geology,

Djusina 7, 11000 Belgrade, Serbia

E-mail: ines.grozdanovic@rgf.bg.ac.rs

\section{Simon SEDMAK, Researche}

Innovation Center of Faculty of Mechanical Engineering

Kraljice Marije 16, 11120 Belgrade, Serbia

E-mail: simon.sedmak@yahoo.com

Blagoj PETROVSKI, senior researcher, PhD

Innovation Center of Faculty of Mechanical Engineering,

Kraljice Marije 16, 11120 Belgrade, Serbia

E-mail: bpetrovski@mas.bg.ac.rs

\section{Contact information:}

Abulgasem SGHAYER, PhD student University of Belgrade, Faculty of Mechanical Engineering, Kraljice Marije 16, 11120 Belgrade, Serbia E-mail:belga1103@yahoo.com

Aleksandar GRBOVIĆ, Prof. PhD

University of Belgrade, Faculty of Mechanical Engineering,

Kraljice Marije 16, 11120 Belgrade, Serbia

E-mail: agrbovic@mas.bg.ac.rs

Aleksandar SEDMAK, Prof. PhD

University of Belgrade, Faculty of Mechanical Engineering

KraljiceMarije 16, 11120 Belgrade, Serbia

E-mail: asedmak@mas.bg.ac.rs

Mirko DINULOVIĆ, Prof. PhD

University of Belgrade, Faculty of Mechanical Engineering

Kraljice Marije 16, 11120 Belgrade, Serbia

E-mail: mdinulovic@mas.bg.ac.rs 